\title{
Expert System to Diagnose Soil and Plant Types According to The Web-Based Forward Chaining Method
}

\section{Sistem Pakar Untuk Mendiagnosa Jenis Tanah dan Tanaman Yang Sesuai Dengan Metode Forward Chaining Berbasis Web}

\author{
Rizal Nur Ramadhan, Suprianto \\ \{rizalnr2@gmail.com, suprianto@umsida.ac.id\} \\ Universitas Muhammadiyah Sidoarjo, Indonesia
}

\begin{abstract}
Soil is a planting medium for farming which is used especially from the agricultural sector to produce various types of commodities from all types of plants. Meanwhile, there are several problems that occur in the middle of agriculture, one of which is the problem of soil acidity which results in a decline in crop yields which before the acidity of the soil did not have so many obstacles in farming. The purpose of this research is to produce an expert system application to diagnose suitable soil and plant types. The research method used is forward chaining, a method that seeks conclusions based on facts that are useful for farmers to be able to find out the ability of the type of soil they experience, so that farmers can handle the appropriate type of soil and plants. The results of this study use an expert system application that has been tested by several farmers to produce a diagnosis of the ability of the soil type so that it can determine the type of soil and plants that are suitable and also as a medium of consultation for farmers. So it can be concluded that the Forward Chaining Expert System is quite feasible to be used by users, in this case farmers, in diagnosing the ability of soil types.
\end{abstract}

Keywords - Expert System; Forward Chaining; Soil Type

Abstrak. Tanah ialah media tanam untuk bercocok tanam yang digunakan khususnya dari sektor pertanian untuk menghasilkan berbagai jenis komoditi dari segala jenis tanaman. Sementara itu beberapa permasalahan yang terjadi di tengah pertanian, salah satu di antaranya masalah keasaman tanah yang mengakibatkan kemerosotan hasil panen yang mana sebelum terjadi asamnya tanah tidak begitu banyak kendala di dalam bercocok tanam. Tujuan penelitian ini adalah untuk menghasilkan aplikasi sistem pakar untuk mendiagnosa jenis tanah dan tanaman yang sesuai. Metode penelitian yang digunakan adalah forward chaining sebuah metode yang mencari kesimpulan berdasarkan fakta yang berguna bagi petani untuk dapat mengetahui kemampuan jenis tanah yang di alaminya, sehingga petani bisa menangani jenis tanah dan tanaman yang sesuai. Hasil dari penelitian ini menggunakan aplikasi sistem pakar yang telah di uji coba oleh beberapa petani menghasilkan diagnosa kemampuan jenis tanahnya sehingga dapat menentukan jenis tanah dan tanaman yang sesuai dan juga sebagai media konsultasi bagi petani. Sehingga dapat disimpulkan bahwa Sistem Pakar Forward Chaining cukup layak untuk digunakan oleh pengguna dalam hal ini para petani dalam mendiagnosis kemampuan jenis tanahnya.

Kata Kunci - Sistem Pakar; Forward Chaining; Jenis Tanah

\section{Pendahuluan}

Tanah ialah media tanam untuk bercocok tanam yang digunakan khususnya dari sektor pertanian untuk menghasilkan berbagai jenis komoditi dari segala jenis tanah, Tanah memiliki beberapa fungsi utama untuk menjadi tempat memproduksi tanaman[1]. Sementara tanah merupakan media tanam yang berbasis pH sehingga petani berpengetahuan tentang tanah yang ber $\mathrm{pH}$. Dan memang tanaman bergantung pada ukuran $\mathrm{pH}$ tanah itu.

Pengolahan lahan tanah yang tidak sesuai akibat petani belum mengetahui dan juga memahami bagaimana kondisi tanahnya yang akan dikelola apakah sudah sesuai untuk jenis tanamannya. Dalam melakukan bercocok tanam petani juga harus mengetahui jenis tanah sehingga mengerti tanaman apa yang sesuai pada jenis tanahnya, karena masingmasing daerah juga memiliki berbagai jenis tanah yang berbeda-beda. bahan organik berperan dalam memperbaiki sifat fisik dan kimia tanah [2]. Pada lapisan permukaan pada bumi berasal dari material induk yang telah mengalami beberapa proses lanjut maka disebut tanah, perubahan alami yang terjadi pada tanah yaitu pengaruh pada air, udara, serta terdapat berbagai macam organisme yang baik dan hidup maupun yang mati tanah yang terdiri dari partikelpartikel tertentu yang menghasilkan sifat plastis apabila dalam kondisi basah [3]. Terlihat perubahan yang terjadi pada komposisi, struktur tanah dan juga warna akibat pelapukan tanah [4].Tingkat pada kesuburan tanah yang tinggi dapat menunjukkan tanah yang tinggi dan baik pula tanah yang berkualitas membagikan kemampuan tanah buat menampilkan fungsi kegunaannya penggunaan lahan atau ekosistem, agar dapat membantu produktivitas biologi, dan 
Procedia of Engineering and Life Science Vol. 2. No. 1 October 2021

Seminar Nasional \& Call Paper Fakultas Sains dan Teknologi (SENASAINS $3^{\text {rd }}$ )

Universitas Muhammadiyah Sidoarjo

untuk mempertahankan kualitas pada lingkungan, dan untuk menaikkan kesehatani tumbuhan, hewan, dan juga manusia [5].

Identifikasi masalah yang peneliti dapat yang terjadi di tengah pertanian era ini, salah satu masalah yaitu keasaman tanah yang akan mengakibatkan merosotnya hasil panen, Petani tidak mengetahui kualitas tanah yang mengakibatkan sering terserang hama dan penyakit jamur. Dalam mengetahui kualitas tanah dapat dilakukan yang mampu mendiagnosa kemampuan jenis tanahnya, Dengan adanya permasalahan tersebut maka memanfaatkan teknologi, seperti kecerdasan buatan mampu untuk menirukan kecerdasan seorang ahli pakar dalam bidangnya yang disebut Artificial Inteligence (AI).

Untuk memudahkan petani dalam mengetahui kemampuan jenis tanahnya petani dapat mengerti jenis tanah dan tanaman yang sesuai, maka peneliti membuat "Sistem Pakar Diagnosa Jenis Tanah dan Tanaman Yang Sesuai Dengan Metode Forward Chaining Berbasis Web" yang bertujuan memudahkan para petani dalam melakukan diagnosa menentukan jenis tanah dan tanaman yang sesuai berdasarkan apa yang di alami petani atau pengguna.

\section{METODE}

\section{A. Teknik pengumpulan data}

Pada teknik pengumpulan data yang digunakan dalam membuat perancangan aplikasi sistem pakar untuk mendiagnosa jenis tanah dan tanaman yang sesuai ini dengan cara observasi melakukan pengamatan secara langsung di lapangan, teknik pengumpulan data yang kedua dengan cara melakukan wawancara kepada petani yang bernama bapak Mijan untuk mengetahui kapasitas tentang informasi tanah dan mendapatkan informasi yang diperlukan dalam penelitian.

\section{B. Sistem pakar}

Sistem pakar merupakan sistem program yang ada pada komputer dengan mempresentasikan serta membuat penalaran sebagai pengetahuani dari seseorang ahli pakar pada bidang tertentu untuk menyelesaikan permasalahan dan memberikan solusi. Pada suatu emulsi akan lebih bertenaga daripada simulasi yang hanya memerlukan hal yang memiliki sifat nyata pada beberapa macam bidang atau suatu hal. [6]. Secara umum, sistem ahli (expert system) merupakan sistem ahli pakar yang mengadopsi pengetahuan dari manusia kemudian dipindah ke komputer, supaya komputer bisa menyelesaikan suatu permasalahan seperti halnya yang sering dilakukan oleh para ahli pakar [7]. Sedangkan pakar manusia (human expert) merupakan orang yang memiliki penguasaan atas suatu masalah. Berdasarkan pengalamannya, ahli pakar berbagi ilmunya untuk menyelesaikan beberapa persoalan dengan lebih efektif dan efisien. Sistem pakar dapat menyebutkan alasan dari setiap langkah untuk menuju tujuan (goal) dan juga dapat menjawab setiap pertanyaan perihal solusi yang dicapainya, seperti halnya seseorang ahli pakar [8].

\section{Forward chaining}

Para ahli forward chaining yaitu suatu proses pencarian menggunakan metode forward chaining, diawali dari sekumpulan berita informasi fakta yang ada dicari menggunakan basis pengetahuan dan aturan yang sesuai menggunakan fakta yang ada lalu melakukan hipotesa agar mendapatkan kesimpulan. strategi ipenarikan konklusi yang berasal dari beberapa fakta informasi yang sudah diketahui, agar mendapatkan keterangan atau fakta yang baru menggunakan ketentuan premis yang sesuai atau hingga keterangan informasi yang fakta [9]. Metode Forward Chaining ialah sebuah metode dengan pengambilan keputusan secara umum yang digunakan oleh system ahli. Dalam proses pencarian menggunakan metode Forward Chaining yang berawal dari kiri ke kanan, yakni dari premis ke konklusi akhir, dengan metode ini tak jarang disebut juga data driven yaitu pencarian diatur oleh data yang diberikan $[10]$.

\section{Analisa basis pengetahuan}

Basis Pengetahuan Kemampuan jenis tanah, dapat dilihat pada tabel 1

Tabel 1. Basis Pengetahuan

\begin{tabular}{lllcc}
\hline \multirow{2nyy}{*}{ NO } & \multirow{2}{*}{ Kode } & $\begin{array}{c}\text { Kemampuan jenis } \\
\text { tanah }\end{array}$ & Jenis Tanah \\
\cline { 3 - 5 } & & Manah Liat Putih & Tanah Liat Hitam \\
\hline 1 & K01 & Mudah erosi & $\checkmark$ & J02 \\
2 & K02 & Tidak mudah erosi & & $\checkmark$ \\
3 & K03 & Berpotensi jamur & $\checkmark$ &
\end{tabular}


Procedia of Engineering and Life Science Vol. 2. No. 1 October 2021

Seminar Nasional \& Call Paper Fakultas Sains dan Teknologi (SENASAINS $3^{\text {rd }}$ )

Universitas Muhammadiyah Sidoarjo

\begin{tabular}{|c|c|c|c|c|}
\hline 4 & K04 & Tidak berpotensi jamur & & $\checkmark$ \\
\hline \multirow[t]{4}{*}{5} & K05 & tidak mempunyai & & \\
\hline & & kemampuan mengantongi & $\checkmark$ & \\
\hline & & unsur hara untuk waktu & & \\
\hline & & lama & & \\
\hline \multirow[t]{3}{*}{6} & K06 & mempunyai kemampuan & & \\
\hline & & mengantongi unsur hara & & $\checkmark$ \\
\hline & & untuk waktu lama & & \\
\hline \multirow[t]{2}{*}{7} & K07 & kesuburan & & $\checkmark$ \\
\hline & & $\mathrm{pH}>7.0$ & & \\
\hline \multirow[t]{2}{*}{8} & K08 & Tingkat kesuburan $\mathrm{pH}$ & $\checkmark$ & \\
\hline & & $<7.0$ & & \\
\hline \multirow[t]{2}{*}{9} & K09 & Kemampuan menyerap & & $\checkmark$ \\
\hline & & pupuk lebih tinggi & & \\
\hline \multirow[t]{2}{*}{10} & K10 & Kemampuan menyerap & $\checkmark$ & \\
\hline & & pupuk sangat rendah & & \\
\hline 11 & K11 & Lembab & $\checkmark$ & \\
\hline 12 & K12 & Kering & & $\checkmark$ \\
\hline
\end{tabular}

Jenis tanah , dimana J01 adalah tanah liat putih dan J02 adalah tanah liat hitam. Kode K01 sampai K12 menjelaskan tentang kemampuan jenis tanah yang ada pada tanah. Antara kemampuan dan jenis tanah dihubungkan dengan tanda centang. Pada jenis tanah liat putih di mana tanda centang terdapat pada J01, J03, J05, J08, J10, dan J11. Menunjukkan bahwa kemampuan jenis tanah yang dialami oleh petani . Sedangkan dengan kemampuan jenis tanah J02,J04, J06, J07, J09, dan J12,maka menunjukkan kemampuan jenis tanah yang dialami oleh petani adalah tanah liat hitam.

\section{Hasil dan Pembahasan}

\section{A. Perancangan sistem}

Diagram konteks

Diagram konteks merupakan gambaran yang memiliki hubungan entitas luar dibuat diagram sederhana, Admin dan user adalah entitas yang ada.

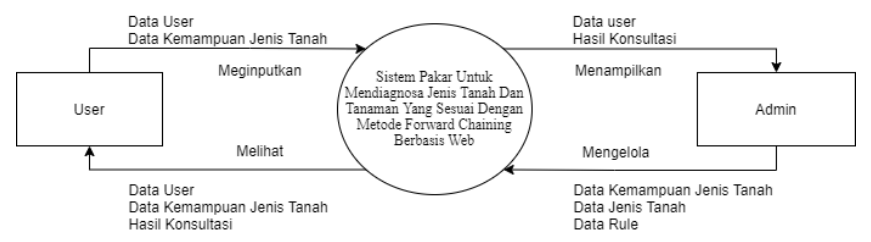

Gambar 1. Diagram Konsteks

Data flow diagram (dfd)

Pada gambar DFD level 1 terdapat admin dan juga user pada proses admin, admin juga dapat mengolahnya. diagram yang dipakai untuk menggambarkan berbagai proses yang terjadi di sistem yang dikembangkan. Dengan menggunakan model inii, seluruh data yang ada pada tiap proses dapat diketahui. 
Procedia of Engineering and Life Science Vol. 2. No. 1 October 2021

Seminar Nasional \& Call Paper Fakultas Sains dan Teknologi (SENASAINS $3^{\text {rd }}$ ) Universitas Muhammadiyah Sidoarjo

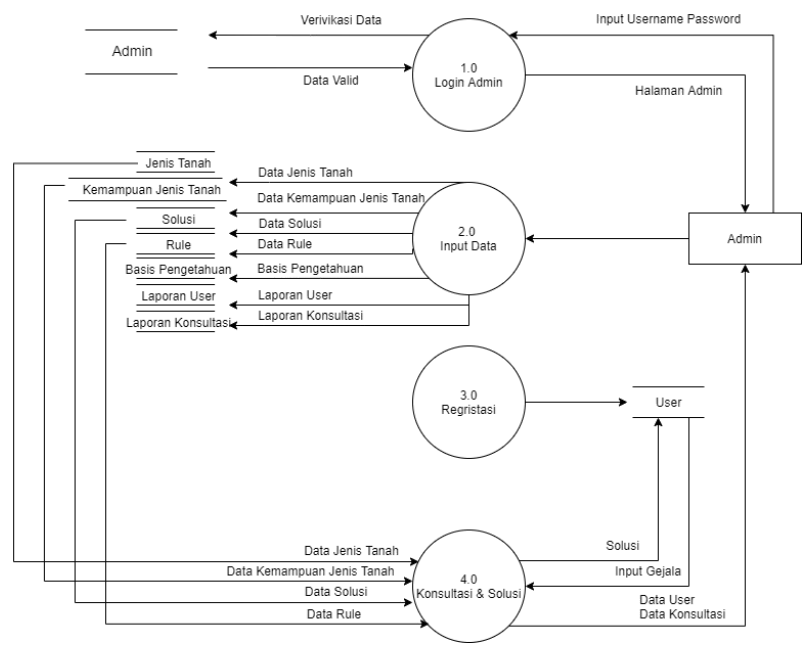

Gambar 2. Data Flow Diagram (DFD)

Entity relationship diagram (erd)

Entity Relation Diagram atau ERD merupakan suatu diagram yang saling berhubungan dengan objek data yang memiliki relasi antar data, ERD sering digunakan untuk membuat struktur data dan di gambarkan,menggunakan notasi,simbol,dan lainnya.

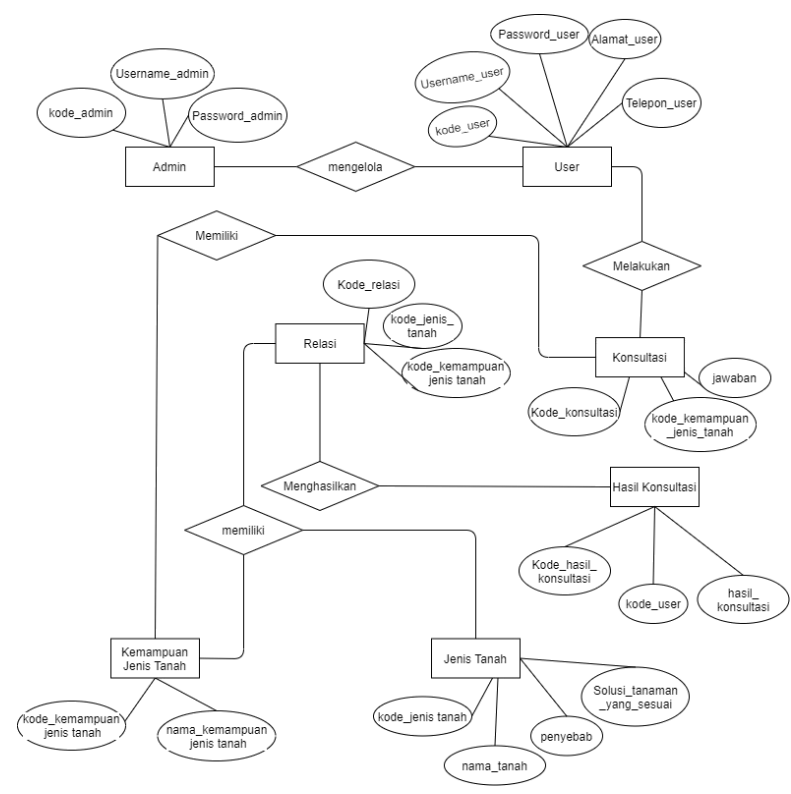

Gambar 3. Entity Relationship Diagram (ERD)

\section{B. User interface aplikasi}

Form registrasi user

Form registrasi user diperuntukkan bagi pengguna untuk melakukan proses membuat akun terlebih dahulu. 
Procedia of Engineering and Life Science Vol. 2. No. 1 October 2021

Seminar Nasional \& Call Paper Fakultas Sains dan Teknologi (SENASAINS $3^{\text {rd }}$ ) Universitas Muhammadiyah Sidoarjo

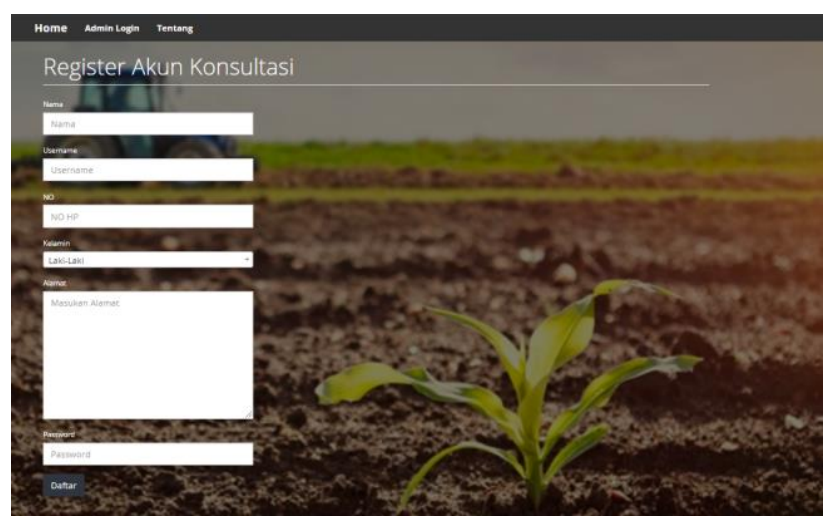

Gambar 4. Form Regristrasi Pengguna

Tampilan user login

Setelah user melakukan registrasi, selanjutnya user login terlebih dahulu agar bisa konsultasi mengenai kemampuan jenis tanah yang di alami oleh user.

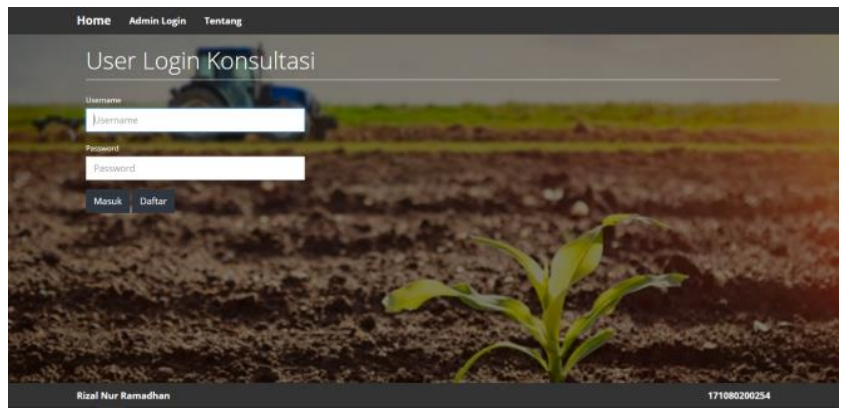

Gambar 5. Tampilan User Login

Tampilan form konsultasi

Pada tampilan form konsultasi user akan melakukan konsultasi dengan menjawab beberapa pertanyaan seputar kemampuan jenis tanah yang di alami oleh user untuk mengetahui jenis tanah dan tanaman nya yang sesuai.

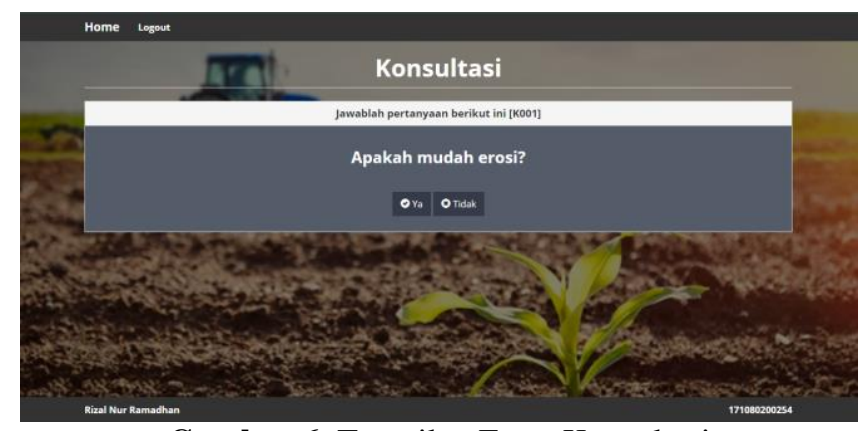

Gambar 6. Tampilan Form Konsultasi

Tampilan halaman hasil diagnosa

Pada tampilan halaman hasil diagnosa akan muncul setelah pertanyaan terjawab, user akan mengetahui jenis tanahnya,ciri-cirinya,dan tanamannya hasil diagnosa berdasarkan jawaban dari user tersebut. User juga bisa mencetak hasilnya 
Procedia of Engineering and Life Science Vol. 2. No. 1 October 2021

Seminar Nasional \& Call Paper Fakultas Sains dan Teknologi (SENASAINS $3^{\text {rd }}$ ) Universitas Muhammadiyah Sidoarjo

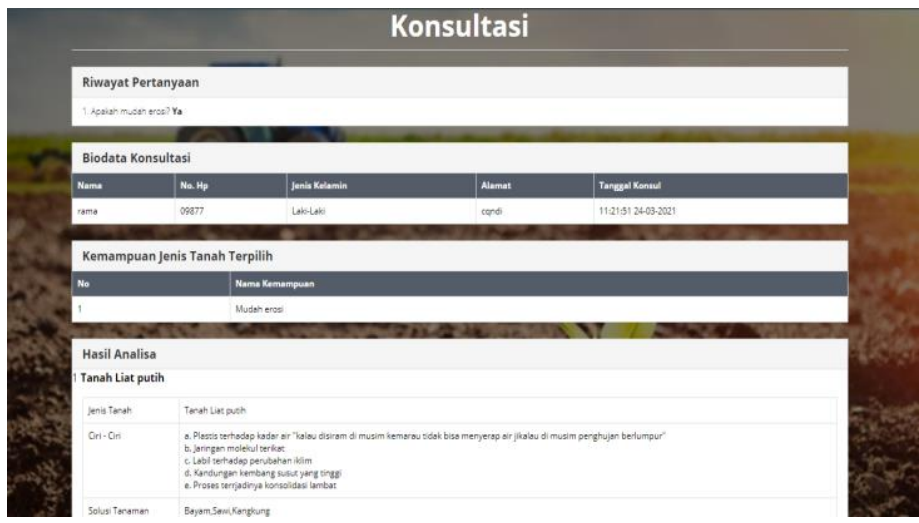

Gambar 7. Tampilan Halaman Hasil Diagnosa

\section{Hasil uji coba sistem}

Pada hasil uji coba sistem ini peneliti melakukan sebuah pengujian aplikasi sistem pakar kepada seorang petani atau user. Petani atau user diminta menggunakan aplikasi sistem pakar untuk konsultasi dan menjawab pertanyaan dari sistem berdasarkan yang di alami oleh petani atau user. Hasil uji coba yang dilakukan oleh petani atau user dapat dilihat pada gambar 8:

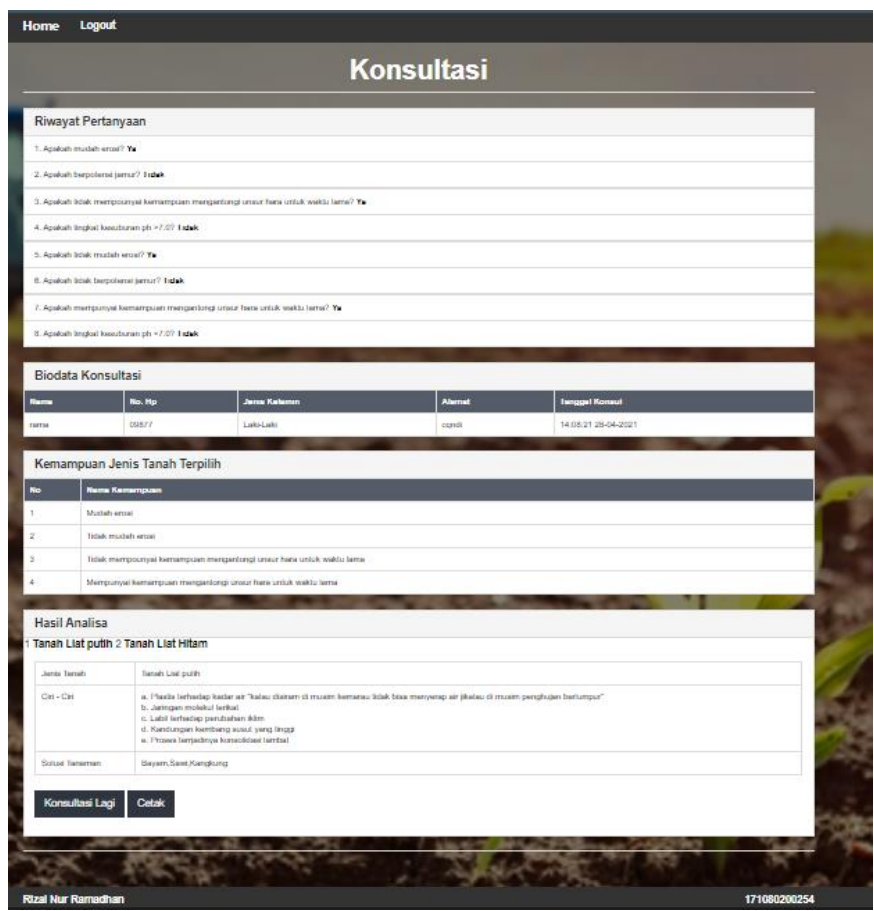

Gambar 8. Hasil Uji Coba Sistem

\section{KESIMPULAN}

Berdasarkan penelitian ini, aplikasi sistem pakar untuk mendiagnosa jenis tanah dan tanaman yang sesuai menggunakan metode forward chaining berbasis web, maka disimpulkan sebagai berikut: (1) Aplikasi ini dapat membantu khususnya para petani dalam memberikan informasi kepada pengguna mengenai karakteristik jenis tanah dan solusi tanaman yang sesuai dengan jenis tanahnya. (2) Sistem pakar untuk mendiagnosa jenis tanah dan tanaman yang sesuai ini dapat dijadikan sebagai media penerapan kecerdasan seorang ahli atau pakar sekaligus menjadi asisten dalam membantu menganalisis dan menentukan jenis tanah. (3) Metode forward chaining mampu memberikan hingga mencapai suatu kesimpulan ciri - ciri dan solusi tanaman yang sesuai untuk setiap jenis tanah. 
Procedia of Engineering and Life Science Vol. 2. No. 1 October 2021

Seminar Nasional \& Call Paper Fakultas Sains dan Teknologi (SENASAINS $3^{\text {rd }}$ )

Universitas Muhammadiyah Sidoarjo

\section{UCAPAN TERIMA KASIH}

Dengan adanya penelitian ini, maka penulis mengucapkan terimakasih banyak kepada semua pihak yang terkait yang sudah membantu dalam melakukan penulisan artikel ilmiah yang berjudul "Sistem Pakar Untuk Mendiagnosa Jenis Tanah Dan Tanaman Yang Sesuai Dengan Metode Forward Chaining Berbasis Web".

\section{REFERENSI}

[1] Sartohadi, Junun, dkk., "Pengantar Geografi Tanah".Yogjakarta. Penerbit Pustaka Pelajar. (2012).

[2] Poerwowidodo. "Telaaah Kesuburan Tanah". Bandung. Penerbit Angkasa. (1992).

[3] Das Braja M. "Mekanika Tanah (Prinsip-Prinsip Rekayasa Geoteknis)”. Jilid 1, Jakarta: Erlangga. (1988).

[4] Dokuchaev. "Mekanika Tanah". Jakarta: Erlangga. (1870).

[5] Winarso, S. "Kesuburan Tanah:Dasar Kesehatan dan Kualitas Tanah". Jogjakarta. Gava media. (2005).

[6] Arhami, Muhammad., "Konsep Dasar Sistem Pakar, Andi”, Yogyakarta. (2005).

[7] Kusumadewi, S., “Artificial Intelligence (Teknik dan Aplikasinya)”, Yogyakarta.Graha Ilmu. (2003).

[8] Riskadewi \& Hendrik, A. "Penerapan Sistem Pakar Forward Chaining Berbasis Aturan pada Pengawasan Status Penerbangan". INTEGRAL. (2005).

[9] Puput.S.D., Ryana.D.L., dan Ryani.T.L., "Sistem pakar diagnosis penyakit ikan koi dengan metode Bayes" Komputa. Jurnal Ilmiah Komputer dan Informatika. (2015).

[10] Hartati, S. dan S. Iswanti. "Sistem Pakar dan Pengembangannya". Edisi Pertama. Yogyakarta.GRAHA ILMU. (2008). 